\title{
Predictors of response to exposure and response prevention-based cognitive behavioral therapy for obsessive- compulsive disorder
}

Sayo Hamatani ${ }^{1,2}$, Aki Tsuchiyagaito ${ }^{1,3}$, Masato Nihei ${ }^{1}$, Yuta Hayashi ${ }^{4,5}$, Tokiko Yoshida ${ }^{1}$, Jumpei Takahashi ${ }^{1}$, Sho Okawa ${ }^{5,6}$, Honami Arai ${ }^{1}$, Maki Nagaoka', Kazuki Matsumoto ${ }^{1}$, Eiji Shimizu ${ }^{1,4,7}$ and Yoshiyuki Hirano ${ }^{1 *}$ (i)

\begin{abstract}
Background: Cognitive behavioral therapy (CBT), which includes exposure and response prevention (ERP), is effective in improving symptoms of obsessive-compulsive disorder (OCD). However, whether poor cognitive functions and autism spectrum disorder (ASD) traits affect the therapeutic response of patients with OCD to ERPbased CBT remains unclear. This study aimed to identify factors predictive of the therapeutic response of Japanese patients with OCD to ERP-based CBT.

Methods: Forty-two Japanese outpatients with OCD were assessed using the Wechsler Adult Intelligence Scale-III (WAIS-III), Yale-Brown Obsessive-Compulsive Scale, Patient Health Questionnaire 9-item scale, and Autism Spectrum Quotient (AQ) at pre- and post-treatment. We used multiple regression analyses to estimate the effect on therapeutic response change. The treatment response change was set as a dependent variable in multiple regression analyses.
\end{abstract}

Results: Multiple regression analyses showed that among independent variables, communication as an AQ subscale and Letter Number Sequencing as a WAIS-III sub-test predict the therapeutic response to ERP-based CBT .

Conclusions: Our results suggest that diminished working memory (Letter Number Sequencing), poor communication skill (AQ sub-scale) may undermine responsiveness to ERP-based CBT among patients with OCD.

Trial registration: UMIN, UMIN00024087. Registered 20 September 2016 - Retrospectively registered (including retrospective data).

Keywords: Obsessive-compulsive disorder, Exposure and response prevention, Cognitive behavioral therapy, Therapeutic response

\footnotetext{
* Correspondence: hirano@chiba-u.jp

'Research Center for Child Mental Development, Chiba University, Inohana, Chuo-ku, Chiba 2608670, Japan

Full list of author information is available at the end of the article
}

(c) The Author(s). 2020 Open Access This article is licensed under a Creative Commons Attribution 4.0 International License, which permits use, sharing, adaptation, distribution and reproduction in any medium or format, as long as you give appropriate credit to the original author(s) and the source, provide a link to the Creative Commons licence, and indicate if changes were made. The images or other third party material in this article are included in the article's Creative Commons. licence, unless indicated otherwise in a credit line to the material. If material is not included in the article's Creative Commons licence and your intended use is not permitted by statutory regulation or exceeds the permitted use, you will need to obtain permission directly from the copyright holder. To view a copy of this licence, visit http://creativecommons.org/licenses/by/4.0/ The Creative Commons Public Domain Dedication waiver (http://creativecommons.org/publicdomain/zero/1.0/) applies to the data made available in this article, unless otherwise stated in a credit line to the data. 


\section{Background}

Obsessive-compulsive disorder (OCD) is a psychiatric disorder characterized by repeated compulsive and obsessive behavior, and its 12-month prevalence in the world is 1.1 to $1.8 \%$ (DSM-5) [1]. NICE guidelines recommend the use of CBT including exposure response prevention (ERP) as a first-line of treatment for OCD, and selective serotonin reuptake inhibitors (SSRI) or more intensive CBT including ERP or combined treatment (CBT including ERP plus SSRI) for moderate to severe OCD [2]. With a treatment response change of approximately 45 to $70 \%[2,3]$, the efficacy of the CBT including ERP has been demonstrated [4-7]. However, about $20 \%$ of OCD don't have good enough response to ERP [3]. Numerous studies have been conducted on cognitive functions of individuals to account for their lack of response to CBT including ERP [8-11]. Neuropsychological functioning has so far been studied as a predictor of the responsiveness of patients with OCD to CBT including ERP, but the results are inconsistent [8-11]. Predictor variables of CBT including ERP for OCD can be classified into various categories [12]: demographic variables; OCD symptom characteristics such as severity; comorbidities and associated symptom severity; cognitive influences; motivational factors such as treatment expectations; treatment factors such as compliance and therapeutic alliance; biological factors; other factors such as personality, family dysfunction, and treatment-specific characteristic [12, 13].

Previous studies have suggested that responses to CBT including ERP are diminished among patients whose symptoms overlap with autism spectrum disorder (ASD) criteria [14, 15]; treatment resistance may thus be attributable the presentation of ASD characteristics. Moreover, severe major depressive disorder has been shown to inhibit therapeutic response to CBT including ERP [12]. It has also been suggested that the severity of obsessive-compulsive symptoms and beliefs may influence the response to CBT including ERP treatment [16]. Conversely, several previous studies have reported that comorbidities such as depression and anxiety do not affect treatment responsiveness to CBT including ERP [17-19]. Therefore, the results are inconsistent [12-19], and further research is needed to identify predictors of response to CBT including ERP.

Furthermore, no studies have examined the factors that affect treatment effects including the full-version of the WAIS for patients with OCD. Specifying people that need an adapted treatment strategy is very important, and it is necessary to specify predictors of treatment response. Here, the present study aimed to elucidate factors related to therapeutic responses to ERP-based CBT, focusing on ASD propensity, cognitive function, OCD severity, and depression severity.

\section{Methods}

\section{Study design}

The present study was included patients who visited the Cognitive Behavioral Therapy Center of Chiba University between March 2013 to May 2018; it included 106 patients who were diagnosed with OCD by a psychiatrist using the Structured Clinical Interview for DSM-IV Axis I Disorders [20]. At the time of the visit to our center, the patient was already diagnosed with OCD at another institution, and he/she brought a referral letter. The diagnosis and evaluation were performed by a welleducated psychiatrist and clinical psychologist at the IAPT of Chiba University. The exclusion criteria were any organic central nervous system disorder, psychosis, intellectual disability, high risk of suicide, substance abuse or dependence, or unstable medical condition; patients for whom cognitive function could not be measured in terms of outcomes and those who did not complete the ERP intervention were also excluded. A total of 64 patients were therefore excluded, so that eventually 42 patients (mean age $=33.2$ years, standard deviation $=7.6$ years, female $=26$, male $=16$ ) with OCD were included in the analysis (Fig. 1). Moreover, none of the participants were diagnosed with attention deficit hyperactivity disorder. Nine patients were pharmacotherapy-free, and 33 patients were taking psychotropic drugs at the time of assessment [29 patients (SSRI), 2 patients (Noradrenergic and specific serotonergic antidepressant), 5 patients (Tricyclic antidepressant), 17 patients (Benzodiazepine), 6 patients (Dopamine system stabilizer), 2 patients (Dopamine serotonin antagonist), 1 patient (Serotonin-dopamine antagonist), 3 patients (Multi-acting receptor targeted antipsychotic), 2 patients (Benzamide antipsychotics), 2 patients (Branched fatty acid), and 1 patient (Butyrophenone)](See supplemental material).

\section{Intervention}

ERP-based CBT was performed on patients with OCD according to a treatment manual created by our research group designed for adult outpatients with OCD(https:// www.mhlw.go.jp/file/06-Seisakujouhou-12200000-Shakaiengokyokushougaihokenfukushibu/0000113840.pdf). The modules were derived from a previous study on inperson ERP for OCD in Japan [7]; these modules included psychoeducation, exposure exercises, and homework assignments [7]. Sixteen ERP-based CBT sessions of $50 \mathrm{~min}$ in length were scheduled each week. All therapists who participated in this study completed the Improving Access to Psychological Therapies project at Chiba University [21]. The quality of ERP-based CBT was controlled through weekly group supervisions led by a psychiatrist. It was recommended that the therapist should record the content of the session using videography and an integrated chip (IC) recorder. However, it 


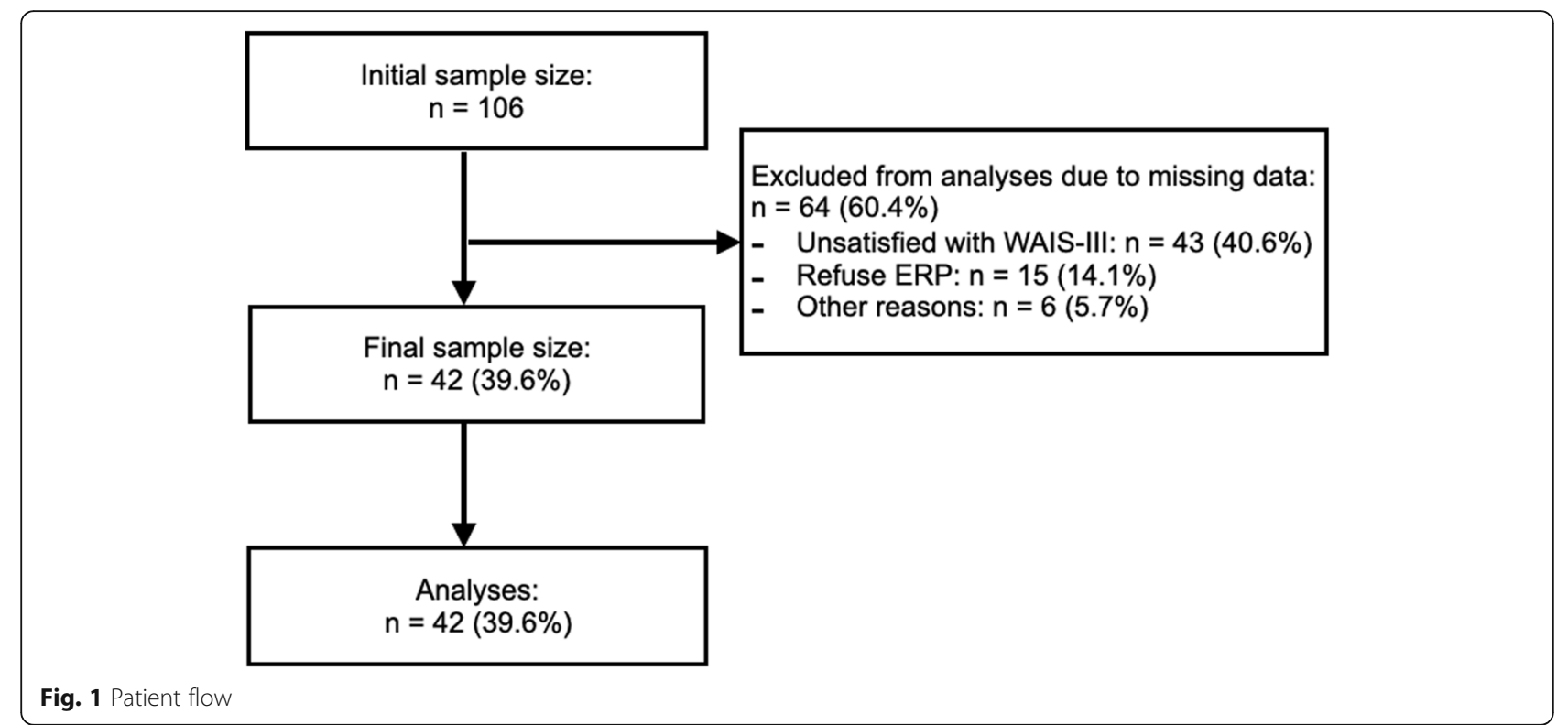

was possible for the patient to refuse to consent to this recording.

\section{Outcomes}

\section{Yale-Brown obsessive-compulsive scale}

To assess the severity of the obsessive-compulsive symptoms, we used the Yale-Brown Obsessive-Compulsive Scale (Y-BOCS) [22, 23]. This scale consists of 10 items (5 obsessions and 5 compulsive items). The questionnaire items are scored on a 4-point Likert-scale; with $0=$ no symptoms to $4=$ extreme symptoms. The total score range is $0-40$, with individual subtotals for obsessions and severity of obsessions. This scale was used in a semi-structured interview setting.

\section{Obsessive-compulsive inventory}

The Obsessive-Compulsive Inventory (OCI) consists of 42 items and is a 5-point Likert-scale [24, 25]. It consists of seven subscales (washing, checking, doubting, ordering, obsessions, hoarding, and neutralizing).

\section{Patient health Questionnaire-9}

The presence and severity of symptoms of depression experienced in the previous 2 weeks were evaluated using the Patient Health Questionnaire-9 (PHQ-9) [26, 27]. The self-administered questionnaire items are scored on a 4-point Likert-scale; with $0=$ not at all to $3=$ almost every day. The total score range is $0-27$ ( 0 to 4 indicates no symptoms, 5 to 9 indicates mild symptoms, 10 to 14 indicates moderate symptoms, 15 to 19 indicates moderate to severe symptoms, and 20 to 27 indicates severe symptoms). The cut-off score for clinically significant symptoms of depression is 10 .

\section{Generalized anxiety disorder - 7 (GAD-7)}

The presence and severity of generalized anxiety disorder was assessed using the GAD-7 [28, 29], a selfadministered questionnaire that assesses the severity of generalized anxiety disorder in the previous 2 weeks on a 4-point Likert scale; with $0=$ not at all to $3=$ almost every day. The total score range is $0-21$ ( 0 to 4 indicates no symptoms, 5 to 9 indicates mild symptoms, 10 to 14 indicates moderate symptoms, and 15 to 21 indicates severe symptoms). The cut-off score for clinically significant symptoms of anxiety is 10 .

\section{Autism-spectrum quotient}

Autism-spectrum Quotient (AQ) is a self-managed instrument that can use any of the dichotomous evaluations to measure autistic characteristics [30, 31]. The total score range is $0-50$. It consists of five subscales (social skills, attention switching, attention to detail, communication, and imagination). The cut-off score for clinically significant symptoms of ASD is 33 .

\section{Wechsler adult intelligence scale-third edition}

The Wechsler Adult Intelligence Scale-third edition (WAIS-III) is a comprehensive test of intellectual functioning [32, 33]. A total of 13 subtests assessing either verbal IQ (VIQ) or performance IQ (PIQ) were administered to patients with OCD. The subtests evaluating VIQ included Vocabulary, Similarities, Information, Comprehension, Arithmetic, Digit Span, and LetterNumber Sequencing; those assessing PIQ included Picture Completion, Block Design, Matrix Reasoning, Visual Puzzles, Digit Symbol Coding, and Symbol Search. The Object Assembly subtest was excluded from the present analysis because it has a lower confidence factor 
than the other subtests [34]. The aforementioned subtests were grouped into the following four indices: VCI (Vocabulary, Similarities, and Information), POI (Picture Completion, Block Design, Matrix Reasoning), WMI (Digit Span and Arithmetic, and Letter-Number Sequencing), and PSI (Symbol Search and Digit Symbol Coding).

\section{Statistical analysis}

The statistical analysis was performed using SPSS Statistics, version 26.00 (IBM Corp., Armonk, NY, USA). To investigate the predictive effects that patient pretreatment background may have had on the treatment response change post treatment, a series of analyses were performed. First, the treatment response change was obtained in terms of the difference between pre- and posttreatment Y-BOCS scores. Next, Pearson correlation coefficients were used to investigate the factors affecting the ERP-based CBT response change and to explore the relationships between such changes and other clinical variables including age, sex, severity of obsessivecompulsive symptoms in Y-BOCS at pretreatment, the traits associated with the autistic spectrum in AQ total scores or its sub-scales, intelligence index in WAIS-III or its sub-tests, OCI total score or its sub-scales, and severity of depression in PHQ-9. Finally, forward stepwise regression analysis was performed with the variables that remained significant in the correlation analysis as independent variables and the ERP-based CBT response change as the dependent variable. Moreover, the unpaired t-test was used to compare the ERP-based CBT plus pharmacotherapy group and ERP-based CBT without pharmacotherapy group, to investigate the effects of medication.

\section{Results}

Demographic and clinical characteristics and WAIS scores of patients with OCD are shown in Table 1. The correlations between the ERP-based CBT response change and other clinical variables in OCD group are presented in Table 2. Significant differences in the ERPbased CBT response change were observed according to sex $(p=0.017)$, Attention switching $(p=0.029)$, Communication $(p=0.026)$, and Letter Number Sequencing $(p=0.005)$. No significant correlation was found between the ERP-based CBT response change and any other clinical variable. Multiple regression analysis was performed with sex, communication, attention switching, and Letter Number Sequencing as explanatory variables and the ERP-based CBT response change as the dependent variable. Multiple regression analyses showed that communication as an AQ sub-scale and Letter Number Sequencing as a WAIS-III sub-test were significant predictors of ERP-based CBT response, if sex and attention switching were excluded for a better fit (Table 3). To investigate the effects of medication, the comparison of the treatment response of the ERP-based CBT plus pharmacotherapy group and ERP-based CBT without pharmacotherapy group did not reveal any significant differences $(\mathrm{t}(40)=0.876, p<0.386)$.

\section{Discussion}

The present study investigated whether clinical symptoms and cognitive functions are predictive of differential therapeutic response to ERP-based CBT among patients with OCD. We found that the ERP-based CBT response change was affected by diminished working memory as a Letter Number Sequencing and poor communication skill as an AQ subscale in Japanese participants with OCD.

A retrospective study of randomized control trials assessing 108 obsessive-compulsive patients receiving selective serotonin reuptake inhibitors reported that comorbidity affected treatment response [35]. Our results were not consistent with those of a previous study [35]. The results of the present study suggest that depressive mood severity was excluded, but that partial ASD propensity impairs treatment response. A previous review has suggested that CBT including ERP for obsessivecompulsive disorder with ASD is effective [36], but that the response to CBT including ERP is relatively poor [15]. The novelty of this study was that the ability to communicate in $\mathrm{AQ}$ predicted treatment response. Without good communication, it is difficult to set appropriate therapeutic goals and exposure tasks. Therefore, it is natural that communication disorder, one of the core disorders in ASD [1], impairs treatment response.

The results of this study did not suggest that OCI's sub-tests predict of response to ERP-based CBT. A subtype of obsessive-compulsive disorder, the hoarding state, was reported to reduce patient outcomes due to adherence [37]. Additionally, a previous study showed that reductions in obsessive beliefs influenced improvements in patients with OCD [38], which are inconsistent with the results of the present study. Previous studies suggested that patient consensus on therapeutic goals and tasks is probably also an important factor in implementing CBT including ERP $[39,40]$. The present study did not measure patients' adherence to ERP-based CBT or the degree of agreement on treatment. Future research should consider these as well. A previous representative study suggested that maleness was predictive of better treatment outcomes [41]. However, our results show that sex was not a predictor of the response to ERP-based CBT, and are consistent with some previous studies for children to adults [18, 42-44].

Although some authors have questioned whether Letter-Number Sequencing can accurately measure 
Table 1 Characteristics and WAIS scores in patients with OCD

No. (male/female)
Age ${ }^{\text {b }}$
Yale-Brown Obsessive-Compulsive Scale
(Y-BOCS) (pre) Total
Yale-Brown Obsessive-Compulsive Scale
(Y-BOCS) (post) Total
ERP-based CBT response change
Obsessive Compulsive Inventory (OCI)
Washing
Checking
Doubting
Ordering
Obsessions
Hoarding
Neutralizing
Total
Patient Health Questionnaire-9 (PHQ-9)
Generalized Anxiety Disorder -7 (GAD-7)
Autism Spectrum Quotient (AQ) AQ
Social skill
Attention switching
Imagination to detail
Cotal

Wechsler Adult Intelligence Scale-III

Full-scale intelligence quotient (FSIQ)
Verbal IQ
Performance IQ

\section{Verbal Comprehension Index (VCl)}

Perceptual Organization Index (POI)

Working Memory Index (WMI)

Processing Speed Index (PSI)

Subtests

Vocabulary
Similarities
Information
Comprehension
Arithmetic
Digit Span
Letter Number Sequencing
Visual Puzzles
Picture Completion

OCD N

Mean \pm SD

$42(16 / 26)$

$33.19 \pm 7.55$

$26.26 \pm 4.10$

$16.00 \pm 8.18$

$10.26 \pm 7.86$

$18.59 \pm 10.81$

$16.62 \pm 9.14$

$7.10 \pm 4.08$

$6.85 \pm 4.62$

$14.26 \pm 5.61$

$3.36 \pm 3.17$

$7.62 \pm 5.01$

$74.30 \pm 26.18$

$12.20 \pm 5.83$

$11.93 \pm 4.51$

$5.13 \pm 2.60$

$6.20 \pm 2.04$

$5.32 \pm 1.82$

$3.95 \pm 2.67$

$4.08 \pm 2.38$

$24.68 \pm 7.76$

$100.95 \pm 10.90$

$102.43 \pm 11.51$

$98.88 \pm 11.40$

$100.95 \pm 11.77$

$100.45 \pm 12.86$

$98.26 \pm 16.30$

$91.17 \pm 17.13$

$10.52 \pm 2.44$

$10.55 \pm 2.47$

$9.38 \pm 2.47$

$12.10 \pm 2.99$

$9.69 \pm 2.67$

$10.99 \pm 3.06$

$9.86 \pm 3.43$

$10.48 \pm 2.80$

$9.67 \pm 2.81$
Table 1 Characteristics and WAIS scores in patients with OCD (Continued)

\begin{tabular}{lll}
\hline & OCD & $N$ \\
& Mean \pm SD & \\
\hline Block Design & $9.67 \pm 3.21$ & 42 \\
Matrix Reasoning & $11.12 \pm 2.60$ & 42 \\
Digit Symbol Coding & $8.69 \pm 2.97$ & 42 \\
Symbol Search & $9.05 \pm 2.62$ & 42 \\
\hline
\end{tabular}

working memory [45], the results of the present study suggested that a subtest of working memory, "Letter Number Sequencing," predicts treatment response. This suggests that the executive function, including working memory, of obsessive-compulsive patients undergoing ERP-based CBT may predict responsiveness. When patients with OCD have poor executive function, they might cannot understand their problem or conduct and complete ERP tasks appropriately. A previous brain imaging study showed that abnormalities in the left dorsolateral prefrontal cortex, a region that has been implicated in working memory [46], negatively affect CBT including ERP outcomes [15]. Mental flexibility, as measured using the California Verbal Learning Test, was predictive of a good response to CBT including ERP; in contrast, it was interesting to note that fluoxetine responsiveness was impaired [9]. Executive function weakness is also known to affect treatment response [9, 4749]. The present study, for the first time in the world, has found that a WAIS-III full-version subtest, Letter Number Sequencing, predicts the response of ERP-based CBT treatment in patients with OCD. In other words, supplementing poor working memory may be beneficial for treatment and results of this study may be helpful to clinicians and cognitive behavioral practitioners choose more effective treatment strategy. In one example, to promote better responsiveness among patients with poor working memory, clinicians can provide more sessions and use visual aids during interventions [50]. Letter Number Sequencing is a simple test that can be performed in about 5 to $10 \mathrm{~min}$. Therefore, clinicians and cognitive behavioral practitioners may be able to estimate response to treatment based on the results of WAIS-III Letter Number Sequencing and AQ communication score before conducting ERP-based CBT in patients with OCD.

This study had several limitations. First, while our findings implicate ASD traits as a risk factor affecting the treatment response change, cohort studies for children and early adolescents have shown that OCD is predicted by beliefs such as intolerance to uncertainty [51]. Since patients with ASD are characterized by intolerance to uncertainty, it remains unclear whether ASD traits itself is a risk factor or whether the intolerance to 
Table 2 Correlations between ERP-based CBT response change and other clinical indices in OCD

\begin{tabular}{llll}
\hline & $N$ & $r$ & $p$-value \\
\hline Age & 42 & 0.12 & 0.455 \\
Sex $^{a}$ & 42 & $0.37^{*}$ & 0.017
\end{tabular}

Autism-Spectrum Questionnaire (AQ)

Social skill
Attention switching
Attention to detail
Communication
Imagination
Total

Y-BOCS (pre) Total

Obsessive Compulsive Inventory (OCl)

\begin{tabular}{|c|c|c|c|}
\hline Washing & 39 & 0.18 & 0.264 \\
\hline Checking & 39 & -0.23 & 0.161 \\
\hline Doubting & 39 & -0.17 & 0.295 \\
\hline Ordering & 39 & 0.00 & 0.994 \\
\hline Obsessions & 39 & -0.10 & 0.529 \\
\hline Hoarding & 39 & -0.22 & 0.186 \\
\hline Neutralizing & 39 & -0.06 & 0.726 \\
\hline Total & 40 & -0.09 & 0.562 \\
\hline PHQ-9 & 41 & $-0.23-0.026$ & 0.142 \\
\hline GAD-7 & 40 & -0.188 & 0.246 \\
\hline Full-scale intelligence quotient (FSIQ) & 42 & 0.08 & 0.621 \\
\hline \multicolumn{4}{|l|}{ WAIS-III Subtests } \\
\hline Vocabulary & 42 & 0.17 & 0.269 \\
\hline Similarities & 42 & 0.00 & 0.981 \\
\hline Information & 42 & -0.01 & 0.955 \\
\hline Comprehension & 42 & 0.05 & 0.740 \\
\hline Arithmetic & 42 & 0.13 & 0.431 \\
\hline Digit Span & 42 & 0.07 & 0.699 \\
\hline Letter Number Sequencing & 42 & $0.42^{* *}$ & 0.005 \\
\hline Visual Puzzles & 42 & -0.14 & 0.365 \\
\hline Picture Completion & 42 & -0.10 & 0.539 \\
\hline Block Design & 42 & 0.15 & 0.333 \\
\hline Matrix Reasoning & 42 & -0.13 & 0.418 \\
\hline Digit Symbol Coding & 42 & 0.21 & 0.178 \\
\hline Symbol Search & 42 & 0.04 & 0.792 \\
\hline
\end{tabular}

${ }^{*} p<0.01,{ }^{* *} p<0.05$

Abbreviations: $O C D$ obsessive-compulsive disorder, $Y$-BOCS Yale-Brown

Obsessive-Compulsive Scale, PHQ-9 Patient Health Questionnaire-9, GAD-7

Generalized Anxiety Disorder-7

${ }^{\mathrm{a}}$ Female $=1$. Male $=0$

uncertainty accounts for the lower responsiveness to ERP-based CBT. To clarify this point, it will be necessary to also use the Obsessive Belief Questionnaire in future investigations. Second, in this study, we found that the
Table 3 Results of stepwise regression analyses on response to ERP-based CBT

\begin{tabular}{llccc}
\hline $\begin{array}{l}\text { Dependent } \\
\text { variable }\end{array}$ & Independent variable & Adjusted $R^{2}$ & $\beta$ & $p$-value \\
\hline Response & Communication & 0.33 & $-0.44^{* *}$ & 0.002 \\
& Letter Number Sequencing & & $0.50^{* *}$ & 0.001 \\
\hline
\end{tabular}

${ }^{* *} p<0.01$

response of ERP-based CBT was not good when the AQ communication score was high. However, AQ is a selfadministered scale, and it is unclear whether this accurately reflects the communication ability. Therefore, it is necessary to measure the quality of communication objectively by behavioral observation, and not by using a self-reported scale. In the future, a more detailed assessment, including the Second Edition of the Autism Diagnosis and Observation Schedule, will be needed to identify ASD [52]. Third, the effects of the participants' medication were not included, because their administration might have changed according to their condition during ERP-based CBT, though we asked the physicians to maintain the medication content and dose constant as much as possible. Research that regulates the content of pharmacotherapy should be conducted in the future.

Fourth, Y-BOCS evaluations were conducted by therapists who were in charge of the patients. Therefore, independent assessors would be needed to evaluate the primary outcomes, including Y-BOCS. Finally, we did not include patients who did not consent to ERP-based CBT in this study, because we could not obtain their post-treatment score (if they did not receive ERP-based CBT) or the reason for refusal.

\section{Conclusions}

Our results suggest that diminished working memory (Letter Number Sequencing), and poor communication skill (AQ sub-scale) score may undermine responsiveness to ERP-based CBT among patients with OCD. The corresponding predictors (working memory, communication skill) of response to ERP-based CBT explain 33\% of the responsiveness to ERP-based CBT among patients with OCD. To validate our findings and overcome the limitations of this study, future research should also consider the intolerance to uncertainty and the quality of ERP-based CBT.

\section{Supplementary information}

Supplementary information accompanies this paper at https://doi.org/10. 1186/s12888-020-02841-4.

Additional file 1. Pharmacotherapeutic agents used by the participants.

\section{Abbreviations}

OCD: Obsessive Compulsive Disorder; CBT: Cognitive Behavioral Therapy;

ERP: Exposure and Response Prevention; WAIS-III: Wechsler Adult Intelligence 
Scale-III; ASD: Autism Spectrum Disorder; Y-BOCS: Yale-Brown ObsessiveCompulsive Scale; PHQ-9: Patient Health Questionnaire-9; AQ: AutismSpectrum Questionnaire

\section{Acknowledgements}

We sincerely appreciate the time and effort of all participants in this study. We also thank the entire staff and all the therapists at the Cognitive Behavioral Therapy Center of Chiba University Hospital.

\section{Authors' contributions}

SH designed the study, analyzed the data, and wrote the manuscript. AT conducted the neuropsychological examinations and critically revised the manuscript for intellectual content. MNi conducted neuropsychological examinations. $\mathrm{YH} 1$ conducted neuropsychological examinations and contributed to the management of the research. TY contributed to the management of the research and conducted neuropsychological examinations. JT contributed to the management of the research. MNa contributed to the funding and administration of the research. SO, HA, and KM critically revised the manuscript for intellectual content. ES discussed the study results and contributed to the final manuscript. $\mathrm{YH} 2$ contributed to the overall supervision of the study and the development of the conclusions. All authors read and approved the final manuscript.

\section{Funding}

This work was supported by AMED [grant number JP20dm0307002] and JSPS KAKENHI [grant numbers 16 K04344, 16 K04342, 19 K03309, and 19 J00227]. The funding sources had no role in the study design; in the collection, analysis and interpretation of data; in the writing of the report; and in the decision to submit the article for publication.

\section{Availability of data and materials}

The datasets generated and/or analysed during the current study are available in the [OSF] repository, [https://osf.io/m7hxb/].

\section{Ethics approval and consent to participate}

Written informed consent was obtained from all participants prior to the assessments, and ethical approval for the present study was granted by the ethics committee of Chiba University (study number 2120). The present study was registered (clinical trial number UMIN000024087) with the University Hospital Medical Information Network Center. The authors assert that all procedures contributing to this work comply with the ethical standards of the relevant national and institutional committees on human experimentation and with the Helsinki Declaration of 1975, as revised in 2008.

\section{Consent for publication}

Not applicable.

\section{Competing interests}

The authors declare that they have no competing interests.

\section{Author details}

${ }^{1}$ Research Center for Child Mental Development, Chiba University, Inohana, Chuo-ku, Chiba 2608670, Japan. ${ }^{2} J a p a n$ Society for the Promotion of Science, Tokyo, Japan. ${ }^{3}$ Laureate Institute for Brain Research, Tulsa, OK, USA. ${ }^{4}$ Department of Cognitive Behavioral Physiology, Graduate School of Medicine, Chiba University, Chiba, Japan. ${ }^{5}$ Graduate School of Medicine and Veterinary Medicine, University of Miyazaki, Miyazaki, Japan. ${ }^{6}$ United Graduate School of Child Development, Osaka University Research Center of Child Mental Development, Chiba University, Chiba, Japan. ${ }^{7}$ Cognitive Behavioral Therapy Center, Chiba University Hospital, Chiba, Japan.

Received: 29 March 2020 Accepted: 27 August 2020 Published online: 04 September 2020

\section{References}

1. American Psychiatric Association. Diagnostic and statistical manual of mental disorders. 5th ed. Washington, DC: American Psychiatric Association; 2013.

2. National Institute of Health and Care Excellence. Obsessive-compulsive disorder and body dysmorphic disorder: treatment. NICE Clinical Guideline CG31, Updated November 2005. Available at: https://www.nice.org.uk/ guidance/cg31/chapter/1-Guidance [Accessed 27th April 2020].
3. Abramowitz JS. The psychological treatment of obsessive-compulsive disorder. Can J Psychiatr. 2006;51:407-16.

4. Hofmann SG, Smits JA. Cognitive-behavioral therapy for adult anxiety disorders: a meta-analysis of randomized placebo-controlled trials. J Clin Psychiatry. 2008;69:621-32.

5. Foa EB, Liebowitz MR, Kozak MJ, Davies S, Campeas R, Franklin ME, Huppert JD, Kjernisted K, Rowan V, Schmidt AB, Simpson HB, Tu X. Randomized, placebo-controlled trial of exposure and ritual prevention, clomipramine, and their combination in the treatment of obsessive-compulsive disorder. Am J Psychiatry. 2005;162(1):151-61.

6. Matsumoto K, Sutoh C, Asano K, Seki Y, Urao Y, Yokoo M, et al. Internetbased cognitive behavioral therapy with real-time therapist support via videoconference for patients with obsessive-compulsive disorder, panic disorder, and social anxiety disorder: pilot single-arm trial. J Med Internet Res. 2018;20:e12091.

7. Nakatani E, Nakagawa A, Nakao T, Yoshizato C, Nabeyama M, Kudo A, et al. A randomized controlled trial of Japanese patients with obsessivecompulsive disorder--effectiveness of behavior therapy and fluvoxamine. Psychother Psychosom. 2005;74:269-76.

8. Braga DT, Abramovitch A, Fontenelle LF, Ferrão YA, Gomes JB, Vivan AS, et al. Neuropsychological predictors of treatment response to cognitive behavioral group therapy in obsessive-compulsive disorder. Depress Anxiety. 2016;33:848-61.

9. D'Alcante CC, Diniz JB, Fossaluza V, Batistuzzo MC, Lopes AC, Shavitt RG, et al. Neuropsychological predictors of response to randomized treatment in obsessive-compulsive disorder. Prog Neuro-Psychopharmacol Biol Psychiatry. 2012;39:310-7.

10. Moritz S, Kloss M, Jacobsen D, Fricke S, Cutler C, Brassen S, et al. Neurocognitive impairment does not predict treatment outcome in obsessive-compulsive disorder. Behav Res Ther. 2005:43:811-9.

11. Vandborg SK, Hartmann TB, Bennedsen BE, Pedersen AD, Thomsen PH. Can memory and executive functions in patients with obsessive-compulsive disorder predict outcome of cognitive behavioural therapy? Nord J Psychiatry. 2016;70(3):183-9.

12. Keley ML, Storch EA, Merlo LJ, Geffken GR. Chinical predictors of response to cognitive-behavioral therapy for obsessive-compulsive disorder. Clin Psychol Rev. 2008;28:118-30.

13. Kyrios M. Exposure and response prevention in the treatment of obsessivecompulsive disorder. In: Menzie R, editor. Obsessive-compulsive disorder: theory, research and treatment. Chichester DSP, England: Wiley; 2003. p. 259-284.

14. Murray K, Jassi A, Mataix-Cols D, Barrow F, Krebs G. Outcomes of cognitive behaviour therapy for obsessive-compulsive disorder in young people with and without autism spectrum disorders: a case controlled study. Psychiatry Res. 2015;228:8-13.

15. Tsuchiyagaito A, Hirano Y, Asano K, Oshima F, Nagaoka S, Takebayashi Y, et al. Cognitive-behavioral therapy for obsessive-compulsive disorder with and without autism spectrum disorder: gray matter differences associated with poor outcome. Front Psychiatry. 2017:8:143.

16. Kyrios M, Hordern C, Fassnacht DB. Predictors of response to cognitive behavior therapy for obsessive-compulsive disorder. Int J Clin Health Psychol. 2015;15:181-90.

17. Knopp J, Knowles S, Bee P, Lovell K, Bower P. A systematic review of predictors and moderators of response to psychological therapies in OCD: do we have enough empirical evidence to target treatment? Clin Psychol Rev. 2013;33:1067-81.

18. Olatuniji BO, Davis ML, Powers MB, Smits JAJ. Cognitive-behavioral therapy for obsessive-compulsive disorder: a meta-analysis of treatment outcome and moderators. J Psychiatr Res. 2013;47:33-41.

19. Steketee G, Shapiro GL. Predicting behavioral treatment outcome for agoraphobia and obsessive compulsive disorder. Clin Psychol Rev. 1995;15:317-46.

20. Spitzer RL, Gibbon M, Williams JBW. User's guide for the structured clinical interview for DSM-IV axis I disorders: SCID-I clinician version. Washington, DC: American Psychiatric Publishing; 1997.

21. Kobori O, Nakazato M, Yoshinaga N, Shiraishi T, Takaoka K, Nakagawa A, et al. Transporting cognitive behavioral therapy (CBT) and the improving access to psychological therapies (IAPT) project to Japan: preliminary observations and service evaluation in Chiba. J Ment Health Train Educ Pract. 2014;9:155-66.

22. Goodman WK, Price LH, Rasmussen SA, Mazure C, Fleischmann RL, Hill CL, et al. The Yale-Brown obsessive compulsive scale. I. Development, use, and reliability. Arch Gen Psychiatry. 1989;46:1006-11. 
23. Hamagaki S, Takagi S, Urushihara Y, Ishisaka Y, Matsumoto M. Development and use of the Japanese version of the self-report Yale-Brown obsessive compulsive scale. Seishin Shinkeigaku Zasshi. 1999;101:152-68.

24. Gönner S, Leonhart R, Ecker W. The obsessive-compulsive inventory-revised (OCI-R): validation of the German version in a sample of patients with OCD, anxiety disorders, and depressive disorders. J Anxiety Disord. 2008;22:73449 .

25. Ishikawa R, Kobori O, Shimizu E. Development and validation of the Japanese version of the obsessive-compulsive inventory. BMC Res Notes. 2014;7:306.

26. Muramatsu K, Miyaoka H, Kamijima K, Muramatsu Y, Yoshida M, Otsubo T, et al. The patient health questionnaire, Japanese version: validity according to the mini-international neuropsychiatric interview-plus. Psychol Rep. 2007; 101:952-60.

27. Spitzer RL, Kroenke K, Williams JB. Validation and utility of a self-report version of PRIME-MD: the PHQ primary care study. Primary care evaluation of mental disorders. Patient health questionnaire. JAMA. 1999;282:1737-44.

28. Muramatsu K. Patient health questionnaire (PHQ-9, PHQ-15) Japanese version and generalized anxiety Disorder-7 Japanese version up to date. Stud Clin Psychol. 2014;7:35-9.

29. Spitzer RL, Kroenke K, Williams JB, Löwe B. A brief measure for assessing generalized anxiety disorder: the GAD-7. Arch Intern Med. 2006;166:1092-7.

30. Baron-Cohen S, Wheelwright S, Skinner R, Martin J, Clubley E. The autismspectrum quotient (AQ): evidence from Asperger syndrome/highfunctioning autism, males and females, scientists and mathematicians. J Autism Dev Disord. 2001;31:5-17.

31. Wakabayashi A, Tojo Y, Baron-Cohen S, Wheelwright S. The autismSpectrum quotient (AQ) Japanese version: evidence from high-functioning clinical group and normal adults. Shinrigaku Kenkyu. 2004;75:78-84.

32. Fujita K, Maekawa H, Dairoku K, Yamanaka K. [A Japanese version of the WAIS-III.] Nihon Bunka Kagakusha. 2006a.

33. Wechsler D. Wechsler adult intelligence scale. 3rd ed. San Antonio: The Psychological Corporation; 1997.

34. Fujita K, Maekawa H, Dairoku K, Yamanaka K. [A Japanese version of the WAIS-III: theoretical manual.] Nihon Bunka Kagakusha. 2006b. pp. 30-39, 5767, 72-75.

35. Maher MJ, Hupper JD, Chen H, Duan N, Foa EB, Liebowitz MR, et al. Moderators and predictors of response to cognitive-behavioral therapy augmentation of pharmacotherapy in obsessive-compulsive disorder. Pyschol Med. 2010:40:2013-23.

36. Kose LK, Fox L, Storch EA. Effectiveness of cognitive behavioral therapy for individuals with autism spectrum disorders and comorbid obsessivecompulsive disorder: a review of the research. J Dev Phys Disabil. 2018;30: 69-87.

37. Maher MJ, Wang Y, Zuckoff A, Wall MW, Franklin M, Foa EB, Simpson HB. Predictors of patient adherence to cognitive-behavioral therapy for obsessive-compulsive disorder. Psychother Psyhosom. 2012;81:124-6.

38. Diedrich A, Sckopke P, Schwartz C, Schlegl S, Osen B, Stierle C, Voderholzer $U$. Change in obsessive beliefs as predictor and mediator of symptom change during treatment of obsessive-compulsive disorder - a processoutcome study. BMC Psychiatry. 2016;16:220.

39. Wheaton MG, Huppert JD, Foa EB, Simpson HB. How important is the therapeutic alliance in treating obsessive-compulsive disorder with exposure and response prevention? An empirical report. Clin Neuropsychiatr. 2016; 13(6):88-93.

40. Matsumoto K, Yoshida T, Hamatani S, Sutoh C, Hirano Y, Shimizu E. Prognosis prediction using therapeutic agreement of video conferencedelivered cognitive behavioral therapy: retrospective secondary analysis of a single-arm pilot trial. JMIR Mental Health. 2019;6:e15747.

41. Foa EB, Grayson JB, Steketee GS, Doppelt HG, Turner RM, Latimer PR. Success and failure in the behavioral treatment of obsessive-compulsives. J Consult Clin Psychol. 1983:51(2):287-97.

42. Piacentini J, Bergman RL, Jacobs C, McCracken JT, Kretchman J. Open trial of cognitive behavior therapy for childhood obsessive-compulsive disorder. J Anxiety Disord. 2002;16:207-19.

43. Benazon NR, Ager J, Rosenberg DR. Cognitive behavior therapy in treatment-naïve children and adolescents with obsessive- compulsive disorder: an open trial. Behav Res Ther. 2002;40:529-39.

44. Moritz S, Fricke S, Jacobsen D, Kloss M, Wein C, Rufer M, et al. Positive schizotypal symptoms predict treatment outcome in obsessive-compulsive disorder. Behav Res Ther. 2004;42:217-27.
45. Reinecke MA, Beebe DW, Stein MA. The third factor of the WISC-III: It's (probably) not freedom from distractibility. J Am Acad Child Adolesc Psychiatry. 1999;38(3):322-8.

46. Barbey AK, Koenigs M, Grafman J. Dorsolateral prefrontal contributions to human working memory. Cortex. 2013;49:1195-205 https://doi.org/10.1016/ j.cortex.2012.05.022

47. Moritz S. Neurocognitive functioning in OCD before and after treatment. CNS Spectr. 1999:4:21-2.

48. Cavedini P, Riboldi G, D'Annucci A, Belotti P, Cisima M, Bellodi L. Decisionmaking heterogeneity in obsessive-compulsive disorder: ventromedial prefrontal cortex function predicts different treatment outcomes. Neuropsychologia. 2002;40(2):205-11. https://doi.org/10.1016/s00283932(01)00077-x.

49. Fontenelle L, Marques C, Engelhardt E, Versiani M. Impaired set-shifting ability and therapeutic response in obsessive-compulsive disorder. J Neuropsychiatry Clin Neurosci. 2001;13(4):508-10. https://doi.org/10.1176/ jnp.13.4.508.

50. van Steensel FJ, Bögels SM, Perrin S. 2011. Anxiety disorders in children and adolescents with autistic spectrum disorders: a meta-analysis. Clin Child Fam Psychol Rev. 2011;14:302-17 https://doi.org/10.1007/s10567-011-0097-0.

51. Pozza A, Albert U, Dèttore D. Perfectionism and intolerance of uncertainty are predictors of OCD symptoms in children and early adolescents: a prospective, cohort, one-year, follow-up study. Clin Neuropsychiatry. 2019; 16:53-61.54.

52. Lord C, Rutter M, DiLavore PC, Risi S, Gotham K, Bishop SL. Autism diagnostic observation schedule. 2nd ed. (ADOS-2) manual (part I): modules 1-4. Western Psychological Services: Torrance, CA; 2012.

\section{Publisher's Note}

Springer Nature remains neutral with regard to jurisdictional claims in published maps and institutional affiliations.
Ready to submit your research? Choose BMC and benefit from:

- fast, convenient online submission

- thorough peer review by experienced researchers in your field

- rapid publication on acceptance

- support for research data, including large and complex data types

- gold Open Access which fosters wider collaboration and increased citations

- maximum visibility for your research: over $100 \mathrm{M}$ website views per year

At $\mathrm{BMC}$, research is always in progress.

Learn more biomedcentral.com/submissions 